\title{
Analysis on the Internationalized Talent Strategy of China
}

\author{
Bolun Cao ${ }^{1, ~ a, ~ *, ~ H o n g y i n ~ L v ~} v^{1, b}$ \\ ${ }^{1}$ Qingshui River Campus of University of Electronic Science and Technology of China, Chengdu City, \\ Sichuan Province, China \\ a 4357193302@qq.com, ${ }^{\mathrm{b}}$ luhongyin@uestc.edu.cn \\ *Corresponding author: Bolun Cao
}

Keywords: Chinese colleges and universities; internationalized talent strategy; ways

\begin{abstract}
The boundary-less talent has promoted the inter-state cooperation but also intensified the inter-state competition. Talent competition is an important part that the Chinese government attaches great importance to. This paper is intended to analyze the proposal background and realization ways of the internationalized talent strategy in Chinese colleges and universities in order to provide reference and consideration for the employment and occupational planning of higher talents in China.
\end{abstract}

\section{Background of Implementing Internationalized Talent Strategy in China}

China has promoted the internationalized talent strategy recent years for a variety of reasons, which Can be summarized into the following four main aspects:

The increasing demand for internationalized talents brought about by the economic globalization and closer international cooperation in science \& technology. The internationalization of talents is the inevitable result of the global flow of human resources caused by economic globalization. China plays an important role in the process of world economic globalization. Under the promotion of economic globalization, strengthening international scientific and technological cooperation has become the inevitable choice of all countries. To grasp the trend of world economic recovery and the third industrial revolution, China must strive to achieve major achievements in all areas and enhance its comprehensive strength

The pace of domestic talent internationalization realizes a moderate but stable growth; and the "returning tide" draws the prelude. China is the largest source country of international students in the world; the population growth rate is still continuously increasing by a small margin though it has slowed down in recent years. With the enhancement of China's comprehensive strength and improvement of employment environment, quite a few students abroad choose to return for employment; over $80 \%$ of students return for development. From 1978 to the end of 2016, all kinds of overseas students were up to 4.5866 million in total; of which 1.3625 million students are studying and researching at related stages; 3.2241 million have completed their studies; 2.6511 million choose to return after completing their studies, accounting for $82.23 \%$ of the group that has completed studies. $81.45 \%$ of the returned population possess master degree, $11.09 \%$ own doctoral degree, $7.46 \%$ possess bachelor degree and junior college degree. Hence one can see that the supply of internationalized talents is considerable.

Construction of Chinese higher education steps in a new stage. Chinese higher education level has been greatly improved since the end of last century. There are still problems such as identity consolidation, lack of competition and overlapping in construction of higher education; it is urgent to strengthen the resource integration and innovate the modes of implementation. In order to further deepen the reform of education and promote the development of world-class universities and disciplines, China has formulated a new strategic decision - "double first-class" construction, which is aimed at building first-class teaching staff, training top-notch innovative talents, improving scientific research level, inheriting and innovating excellent cultures, and exerting in promoting achievements transformation. A strong internationalized teacher research team is an important foundation for 
constructing "double first-class" universities. The launch and implementation of the "double first-class" strategy has provided a vast space for the introduction of talents worldwide.

Aged tendency of population in China and the arrival of the third baby boom. The aged tendency of population has been increasingly serious in China; and the population over 60 years old was over 230 million by the end of 2017.China is the only country in the world where the elderly population exceeds 200 million. it is predicted that by 2040, the proportion of the aged population aged 65 and above will exceed $20 \%$ of the total population. The demographic dividend is an important factor for keeping long-term and rapid development; however, the aging of the population, especially the aging of the workforce, will lead to a decline in the proportion of the working-age population, which may make our nation lose the strength of human resources. As the second baby boomers have marries, settled down and entered the child-bearing age, and with the comprehensive liberalization of two children policy, the number of newborns has increased. The number of births in 2016 was up to 17.860 million, increasing 1.4 million than that during "12th Five-Year Plan" period, increasing 1.91 million than that in 2015; 2016 became the highest birth year since 2000. According to the data from State Statistical Bureau, the number of children aged 0-14 years was about 242 million in China, with a huge total amount; and the huge population base determined the huge demands for education. In view of the population structure of China, our nation must increase the introduction of higher talents.

\section{The Internationalized Talent Strategy of China}

For the sake of meeting the requirements of China's economic development and international scientific and technological cooperation on international talents and promote the development of higher education construction, and make up for the lack of domestic population structure, the Chinese government has issued a series of internationalized talent strategies in recent years, which has guided the direction for training internationalized talents from the perspective of policy.

The ministry of human resources and social security (MHRSS) plans and leads "millions of national candidates for talent programs "It is a national training program for major talents jointly organized and implemented by MHRSS and other seven ministries and commissions in order to further strengthen the construction of high-level professional and technical talent team, Accelerate the training and training of young academic leaders; It aims at the end of the 20th century, in the field of natural science and social science to create many trans-century academic and technical leaders and backup candidates, to the national economy and social development have a significant impact. The "Millions of Talent Projects" is oriented by the principle of training (rather than selecting).

The "Ten Thousand Talents Program" and "Thousand Talents Program" coordinated and led by Organization Department of the CPC Central Committee. In December 2008, the central government decided to implement the "Thousand Talents Program" to introduce overseas high-level talents and use 5 - 10 years to introduce and support a batch of talents to return (come to China) for innovation and Entrepreneurship based on the strategic goal for national development in key national innovation projects, key disciplines and key laboratories, central enterprises and financial institutions, as well as all kinds of parks centered by high-tech industrial development zones. To strengthen the construction of high-level innovative and entrepreneurial talents requires "two hands"; one hand grasps the introduction of high-grade overseas talents, and the other focuses on the encouragement and cultivation of domestic talents. On account of this, the central government explicitly proposed in consideration of "Thousand Talents program" at the end of 2008 that it would formulate and implement the national support plan for domestic high-level talents and maximize the innovative and entrepreneurial vitality of various domestic talents. The National Special Support Program for High-level Talent (also known as the "Ten Thousand Talents Program") was officially launched and carried out in September 2012. It is a major national talent project in parallel with the "Thousand Talents Program" that introduces high-level overseas talents, with the overall goal of selecting and supporting about 10,000 high-level innovative \& entrepreneurial talents within 10 years.

The "Changjiang Scholars Program" coordinated and led by Ministry of Education. This is a special plan jointly funded by the ministry of education of the People's Republic of China and Mr. Li jiacheng, the patriotic industrialist of Hongkong in 1998 for improving the academic status of 
Chinese universities and prospering China's higher education. This program includes two parts: implementation of specially-invited professor post system and Changjiang scholar achievement award; based on these, it has the main purpose of recruiting a large number of young and middle-aged academic elites at home and abroad to participate in the construction of key disciplines in China's higher schools and drive these key disciplines to catch up with or maintain the international advanced level; training and cultivating a group of academic leaders with international leading levels in several years so as to greatly enhance the worldwide academic status and competitiveness. At the same time, this implementation will play an important role in promoting the reform of employment system and distribution system in China's higher schools, breaking the ownership and job lifelong tenure system of talent units, and changing the equalitarianism in distribution.

The "Innovative Talent Promotion Plan" coordinated and led by the Ministry of Science and Technology. The ministry of science and technology organized the implementation of the national program for medium - and long-term talent development (2010-2020), which is aimed to cultivate and train a number of world-class scientists, advanced science and technology personnel and engineers, outstanding innovation team and entrepreneurial talent, establish innovative demonstration base of personnel training, strengthening the construction of high-level innovative talents of science and technology of tea, guide and promote the development of the science and technology talents through the innovation system mechanism, optimize the policy environment, to strengthen security measures, in order to improve the independent innovation ability and constructing innovative country provide strong support.

The national science foundation for outstanding young people and the national science foundation for outstanding young people are coordinated and led by the national natural science foundation committee. The excellent youth science fund, also known as "small excellent youth", is the paving science and technology support fund for the National Outstanding Youth Fund. In order to further implement the deployment of " National Plan Outline for Medium and Long Term Talent Development", strengthen the training of innovative young talents and perfect the National Natural Science Fund Talent Funding System. Since 2012, the national natural science foundation committee has decided to set up the outstanding youth science fund project. As a kind of talent project series, the outstanding youth science fund project has formed an effective connection with the youth science fund project and the national outstanding youth science fund project, which promotes the rapid growth of innovative young talents and mainly supports the young science \& technology personnel with 5 10 years of scientific research experiences and some scientific achievements to forge ahead, innovate and independently select the research direction to carry out the basic researches at the forefront of scientific research. The "National Outstanding Youth Science Fund" supports the young scholars who have obtained outstanding achievements in basic research to independently select research direction to carry out innovative researches, promotes the growth of young scientists and technicians, attracts overseas talents, and trains the outstanding academic leaders to enter the frontier of science and technology in the world.

\section{Path of Internationalization Strategy for Chinese colleges and Universities}

Establish excellent internationalized teaching staff and perfect the internationalized teaching mode. At present, many foreign subjects are dominated by China. The employment of foreign teachers, especially the specialized courses of foreign teachers, is an important measure to improve the academic level of Chinese college students and build an international perspective. The entry of internationalized teachers not only interrelates teachers at home and abroad in the same environment, but also promotes the deep international exchanges and development of disciplines. In addition, it is also a way to select and send excellent teachers abroad for further study. Through the learning and training over some periods, teachers' abilities can be effectively promoted; and on this basis, it provides a basis and practice for exploring a perfect international teaching mode. In recent years, the popular modes in China such as "3+2", and "summer training" have provided favorable cases for further improving the training of internationalized talents.

Deepen the internationalization of scientific research and perfect the internationalized 
management service organizations. Universities and colleges in China, especially the first-class ones, are equipped with discipline laboratories. These laboratories should actively target the world's frontier topics and break them based on the rich academic resources. The main way to carry out frontier innovation research with the national laboratory as platform and strengthen scientific research cooperation. Enterprises are the most sensitive vane of market demand, whether the local enterprises or multinational enterprises can form a mutually beneficial and win-win situation in the interaction with universities and colleges. In addition, domestic universities and colleges have also conformed to the development trend and established the International Cooperation Office in recent years. Therefore, the issue that how to fully develop the role of this institution is worth discussing. It not only needs to provide broad and comprehensive internationalized services for teachers and students, but also requires to follow up the implementation plan for internationalization strategy in time.

Broaden the internationalized perspective and create an internationalized talents atmosphere. Internationalization has already been a general trend. It broadens students' internationalized vision in daily learning and joins internationalized factors in process of teaching, management and scientific research, which allow the internationalization to be the characteristic of universities. The construction of internationalized atmosphere is very important for training talents. It must enable the students to understand foreign cultures and customs through various ways so that domestic talents can better be internationalized in ideology. Many colleges and universities promote international exchanges among students through cultural exchange seminars, cultural festivals and other forms. It is also noted that students must build up their cultural confidence; In the process of collision and exchange with foreign cultures, they are supposed to possess strong national confidence and pride and treat the internationalization process with an equal mind. Therefore, it is of vital importance to the patriotism and cultural confidence of college students.

\section{Enlightenment of Chinese Internationalized Talent Strategy on Employees}

Pursue higher degree based on high quality. Most of our overseas talents are masters; however, the summary of law of overseas talents market indicates that a higher degree is a knocking brick for a good job. Compared with the internationalized talent strategy issued in China, it is easy to find that the degree of doctor and above are a basic requirement for universities to introduce talents.

Enrich academic achievements through a variety of modes. Education degree is only a knocking brick for entry; and ability is exactly the highlight of career development. Employees should not only acquire high degrees, but also shall possess rich academic resources and academic ability. During the period of school, they should utilize the projects and academic conferences of schools and government to increase experiences, study and explore more academic issues, write high-quality and high-standard academic papers, and improve the discipline specialty.

Establish an internationalized vision and diversify the major selection. The future is still the age of globalisation. In order to grasp the trend of The Times, China's demand for talents also tends to be international. In this regard, employees should set up an international vision, possess the international thinking and ideas, not be limited in the business, management, art and other popular specialties in major selection; they can take full advantages of the most advanced computers and artificial intelligence in the world to complement and contribute to the establishment of Chinese disciplines.

\section{References}

[1] Gao Fuan, Cai Juanjuan, Hou Jun, the strategy of introducing and cultivating high-level talents in colleges and universities, J. Media education.166(2010)127-131

[2] Zhao Jinping, Shan Gu, Strategic analysis of international talents in Japanese universities, J. Research on higher education in China.10 (2014)84-88

[3] Information on http://www.eol.cn/html/lx/report2017/mulu.shtml

[4] Information on http://www.cctv.com/special/1017/-1/86774.html

[5] Information on http://www.chyxx.com/industry/201707/544456.html 